\title{
Impact sports and bone fractures among adolescents
}

Kyle R. Lynch, Han C. G. Kemper, Bruna Turi-Lynch, Ricardo R. Agostinete, Igor H. Ito, Rafael Luiz-De-Marco, Mario A. Rodrigues-Junior \& Rômulo A. Fernandes

To cite this article: Kyle R. Lynch, Han C. G. Kemper, Bruna Turi-Lynch, Ricardo R. Agostinete, Igor H. Ito, Rafael Luiz-De-Marco, Mario A. Rodrigues-Junior \& Rômulo A. Fernandes (2017) Impact sports and bone fractures among adolescents, Journal of Sports Sciences, 35:24, 2421-2426, DOI: 10.1080/02640414.2016.1272708

To link to this article: https://doi.org/10.1080/02640414.2016.1272708

$$
\text { Published online: } 27 \text { Dec } 2016 .
$$

\section{Submit your article to this journal $\longleftarrow$}

Џ Article views: 466

Q View related articles $\sqsubset$

View Crossmark data ¿

Citing articles: 8 View citing articles $\square$ 


\section{Impact sports and bone fractures among adolescents}

Kyle R. Lynch ${ }^{\mathrm{a}, \mathrm{b}}$, Han C. G. Kemperc, Bruna Turi-Lynch ${ }^{\mathrm{a}, \mathrm{b}}$, Ricardo R. Agostinete ${ }^{\mathrm{a}, \mathrm{d}}$, Igor H. Ito ${ }^{\mathrm{a}, \mathrm{b}}$, Rafael Luiz-De-Marco ${ }^{\mathrm{a}}$, Mario A. Rodrigues-Junior ${ }^{a, b}$ and Rômulo A. Fernandes $s^{a, b, d}$

aLaboratory of InVestigation in Exercise (LIVE), Department of Physical Education, Sao Paulo State University (UNESP), Presidente Prudente, Brazil; bPost-Graduation Program in Kinesiology, Institute of Biosciences, Sao Paulo State University (UNESP), Rio Claro, Brazil; 'Department of Occupational Health, EMGO ${ }^{+}$Institute for Health and Care Research, VU University Medical Center, Amsterdam, The Netherlands; ${ }^{\mathrm{d} P o s t-G r a d u a t i o n}$ Program in Physical Therapy, Department of Physical Therapy, Sao Paulo State University (UNESP), Presidente Prudente, Brazil

\section{ABSTRACT}

The objective of the present study was to investigate the effects of different sports on stress fractures among adolescents during a 9-month follow-up period. The sample was composed of 184 adolescents divided into three groups (impact sports [ $n=102]$; swimming $[n=35]$; non-sports $[n=47]$ ). The occurrence of stress fracture was reported by participants and coaches. As potential confounders we considered age, sex, resistance training, body composition variables and age at peak of height velocity. There were 13 adolescents who reported fractures during the 9-month period. Bone mineral density values were higher in adolescents engaged in impact sports $(P$-value $=0.002)$. Independently of confounders, the risk of stress fracture was lower in adolescents engaged in impact sports than in non-active adolescents (hazard ratio $[\mathrm{HR}]=0.23$ [95\% confidence interval $(\mathrm{Cl})=0.05$ to 0.98$]$ ), while swimming practice was not associated to lower risk of fracture ( $\mathrm{HR}=0.49[95 \% \mathrm{Cl}=0.09$ to 2.55$])$. In conclusion, the findings from this study indicate the importance of sports participation among adolescents in the reduction of stress fracture risk, especially with impact sports. More importantly, these results could be relevant for recognising adolescents in danger of not reaching their potential for peak bone mass and later an increased risk of fractures.
ARTICLE HISTORY

Accepted 6 December 2016

KEYWORDS

Stress fractures; bones; motor activity

\section{Introduction}

Sports participation constitutes the most common manifestation of physical activity among adolescents (Strong et al., 2005). In the United States, it is estimated that 30-45 million individuals between 6 and 18 years of age participate in sports (Brenner \& Council on Sports Medicine and Fitness, 2007). In fact, sports participation is capable to promote cardiovascular, metabolic and psychologic benefits during paediatric ages (Strong et al., 2005), as well as improve bone health among adolescents (Tenforde \& Fredericson, 2011). Studies have shown that young athletes involved in impact sports have greater bone mass than non-athletes (Fehling, Alekel, Clasey, Rector, \& Stillman, 1995; Risser et al., 1990). The greatest potential for bone tissue involves jumping activities that contain high forces delivered at a rapid rate (Gunter, Almstedt, \& Janz, 2012). As an example, ball sports (that include jumping, quick changes in direction, sprinting actions and multidirectional forces) may promote higher peak bone mass accrual and improve geometric strength (Agostinete et al., 2016; Tenforde, Sainani, Sayres, Milgrom, \& Fredericson, 2015).

Despite the benefits of sports participation, an increased prevalence of bone injuries in adolescents has raised concerns regarding the safety of intense athletic participation at a young age, since stress fractures can impair growth with potential lifelong effects (Maffulli \& Bruns, 2000). It is estimated that the frequency of injuries related to sports (any sensation of pain, musculoskeletal discomfort or bone fracture that limits the participation of the adolescent at least one day in its usual activities) is about $21 \%$ among adolescents aged 12-18 years (Vanderlei, Vanderlei, Bastos, Netto Júnior, \& Pastre, 2014). On the other hand, the impact of sports participation on risk of injuries in children and adolescents is not clear due to the existence of conflicting data about the role of bone mineral density (BMD) and different kinds of sports in this complex relationship (Löfgren, Dencker, Nilsson, \& Karlsson, 2012; Wren et al., 2012).

In terms of conflicting data about sports and risk of bone fractures, it is relevant to highlight that sports participation improves BMD (Agostinete et al., 2016; Ubago-Guisado, Gómez-Cabello, Sánchez-Sánchez, García-Unanue, \& Gallardo, 2015), but the effectiveness of higher BMD on the prevention against fractures is unclear (Wren et al., 2012). Moreover, the osteogenic effect attributed to sports participation is based on the exposition of bone matrix to mechanical strain, thus it is not known if non-impact sports are effective in reducing the risk of stress fractures when compared to adolescents not engaged in sports, mainly because its osteogenic effect is under discussion (Kemper, 2006; Ribeiro-Dos-Santos et al., 2016).

Thus, considering the advantages on bone health and disadvantages on stress fractures related to participation in sports, the objective of this study was to investigate the 
effects of different sports on stress fractures among adolescents during a 9-month follow-up period. We hypothesised that adolescents engaged in impact sports have lower risk of stress fractures, while adolescents engaged in non-impact sports have about the same risk for stress fractures as those not involved in sports.

\section{Methods}

This longitudinal study was carried out by researchers of the "Laboratory for the InVestigation of Exercise" (LIVE) of the Department of Physical Education, Sao Paulo State University (UNESP), in the city of Presidente Prudente ( 200,000 inhabitants located at western part of Sao Paulo State), Brazil. The study was conducted between October 2013 and July/August 2014 and was previously approved by the ethical board of UNESP, Presidente Prudente.

The study was presented to the Department of Sports (responsible for all public sports clubs), Department of Education (responsible for all public and private schools) and private sports clubs (located at metropolitan region and other cities around). Coaches and principals were contacted after authorisation of their respective departments. At baseline, the following inclusion criteria were adopted: (i) chronological age between 11 and 17 years; (ii) prior authorisation from coach and parents; (iii) a minimum of 6 months of previous practice (sports group) or absence of any organised sports in the last 3 months (control group); (iv) no use of medication that could affect bone metabolism and (v) a signed consent form. The adolescents were contacted in 11 different locations ( 3 public/private schools and 8 sports clubs).

A minimum sample size of 177 adolescents was estimated taking into account an expected occurrence of fractures of $21 \%$ (Vanderlei et al., 2014), error of $6 \%$ and $Z=1.96$. Initially, 190 adolescents with age ranging from 11 to 17 years) were contacted and considered eligible to start the longitudinal study. Six adolescents were excluded during follow-up measurements (Figure 1).

\section{Sports participation}

In overall, 184 adolescents were evaluated at baseline and at the end of follow-up (chronological age distribution: 11 years old, $n=48 ; 12$ years old, $n=54 ; 13$ years old, $n=32 ; 14$ years old, $n=28 ; 15$ years old, $n=10 ; 16$ years old, $n=08 ; 17$ years old, $n=04)$. All participants were divided into three groups according to sports participation: non-sports $(n=47)$, swimming $(n=35)$ and impact sports (soccer, basketball, volleyball, karate, judo and kung-fu [ $n=102])$. Swimmers, soccer players and karate fighters participated in competitions at the national level, while other athletes (judo, basketball, kung-fu and volleyball) were engaged in tournaments at the regional level.

The adolescents and coaches reported the number of days per week involved in the sports, as well as the time (in minutes) spent each day engaged in practice (impact sports, 470.4 min per week $[95 \%$ confidence interval $(\mathrm{Cl})=402.2-$ 538.7] /swimming, $876.1 \mathrm{~min}$ per week $[95 \% \mathrm{Cl}=744.9-$ 1007.1]).

\section{Fracture follow-up}

The occurrence of stress fractures was assessed during the follow-up period. The participants were asked "During the past 9 months, have you experienced any broken bones?" and if the response was "yes", two follow-ups were asked "Which bone was broken?" and "How many times did the break occur?" Following the classification proposed by Wren et al. (2012), the severity of the fractures was identified as lowimpact fractures (e.g., low-impact collision or any fall from low heights), medium-impact fractures (e.g., sports, fighting, bicycling or physical education classes) and high-impact fractures (e.g., any significant trauma impact [automobile accident or fall from high heights]).

\section{Potential confounders}

In a face-to-face interview, the adolescents reported engagement in resistance training (RT) (previous time of practice of

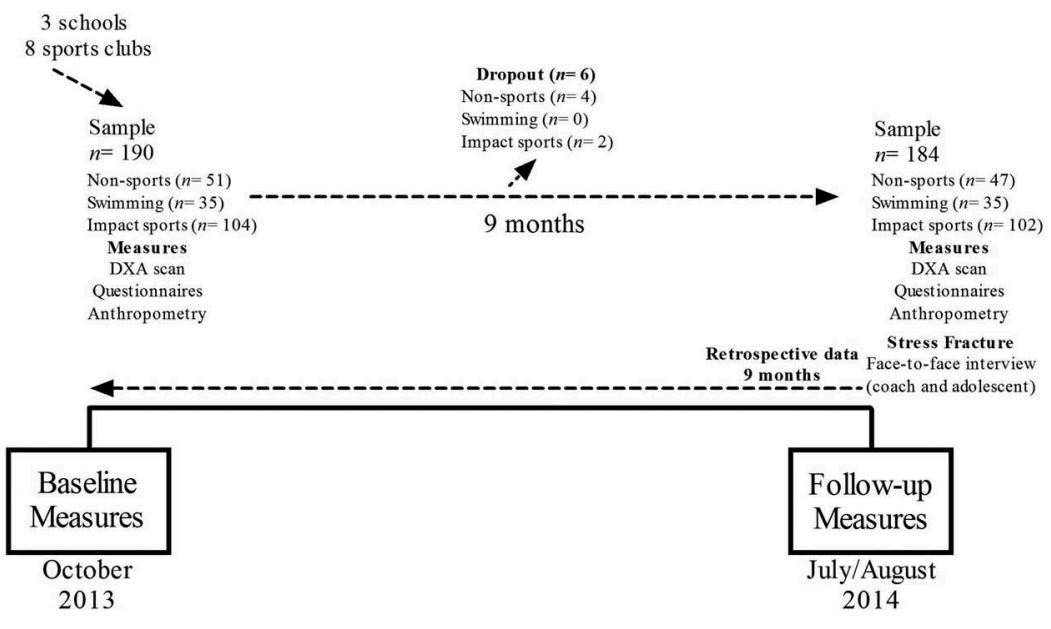

Figure 1. Flow chart of the longitudinal study (Brazil, $n=184$ ). 
RT expressed in months), and coaches confirmed this information. Chronological age and sex were treated as potential confounders too. In both moments of analysis (baseline and follow-up), whole body measurements of body fatness (in percentage), lean soft tissue (LST in $\mathrm{kg}$ ) and BMD $\left(\mathrm{g} / \mathrm{cm}^{2}\right)$ were assessed using a dual-energy x-ray absorptiometry (DXA) scanner (Lunar DPX-NT; General Electric Healthcare, Little Chalfont, Buckinghamshire, UK) with GE Medical System Lunar software (version 4.7). DXA measures were performed in the morning after a light breakfast, and the scanner quality was tested by a trained researcher before each day of measurement, following the manufacturer's recommendations. The participants wore light clothing, without shoes and remained in the supine position on the machine (approximately $15 \mathrm{~min}$ ).

Body weight was measured using an electronic scale (Filizzola PL 150, model Filizzola Ltda, Brazil), and height was measured using a wall-mounted stadiometer (Sanny, model American Medical of the Brazil Ltda, Brazil). The leg length and sitting height were assessed using standardised techniques. These measurements were used to calculate the maturity offset in both moments of the cohort, which denotes the time (years) from/to peak of height velocity (APHV), an important maturational event (Mirwald, Baxter-Jones, Bailey, \& Beunen, 2002).

\section{Statistical analysis}

Descriptive statistic was composed of mean and SD. Categorical variables were expressed as rates (and 95\% Cl) and compared by the $x^{2}$ test (Yates's correction was applied in $2 \times 2$ contingence tables). The impact of sports participation on risk of fracture was estimated by Cox regression and expressed as hazard ratio (HR) and its $95 \% \mathrm{Cl}$. Four multivariate models were created considering the potential confounders. The Model- 1 was simultaneously adjusted by sex, age and height. The Model- 2 was simultaneously adjusted by sex, age, height and RT (time of previous practice, expressed in months). The Model-3 was simultaneously adjusted by sex, age, height, RT and APHV (baseline and follow-up). The Model-4 was simultaneously adjusted by sex, age, height, RT, APHV (baseline and follow-up) and BMD (baseline and accrual). The Model-5 was simultaneously adjusted by sex, age, height, RT, APHV (baseline and follow-up) and LST (baseline).

All statistical analyses were performed in the software BioEstat (release 5.0), and statistical significance ( $P$-value) was set at 0.05 .

\section{Results}

There were 13 stress fractures reported during the 9-month longitudinal study $(7.1 \%[95 \% \mathrm{Cl}=3.3-10.7])$, with 5 fractures in upper limbs, 1 fracture in lower limbs and 7 fractures in other bones. Four bone fractures occurred during sports participation (30.7\% of the overall). Adolescents who reported stress fractures were similar in all variables (age, weight, height, body fatness, LST, somatic maturation and BMD) to those adolescents who did not report fractures (Table 1). Similarly, sex $(P$-value $=1.000), \operatorname{APHV}(P$-value $=0.733)$ and engagement in RT $(P$-value $=0.308)$ were not related with the occurrence of fractures. On the other hand, sports participation was related with lower occurrence of fracture during the 9-month longitudinal study (non-sports $=12.8 \%$, swimming $=8.6 \%$ and impact sports $=3.9 \%$; $P$-value $=0.047$ )

Table 1. Baseline characteristics of the adolescents stratified according to the occurrence of bone fracture during the study $(n=184)$.

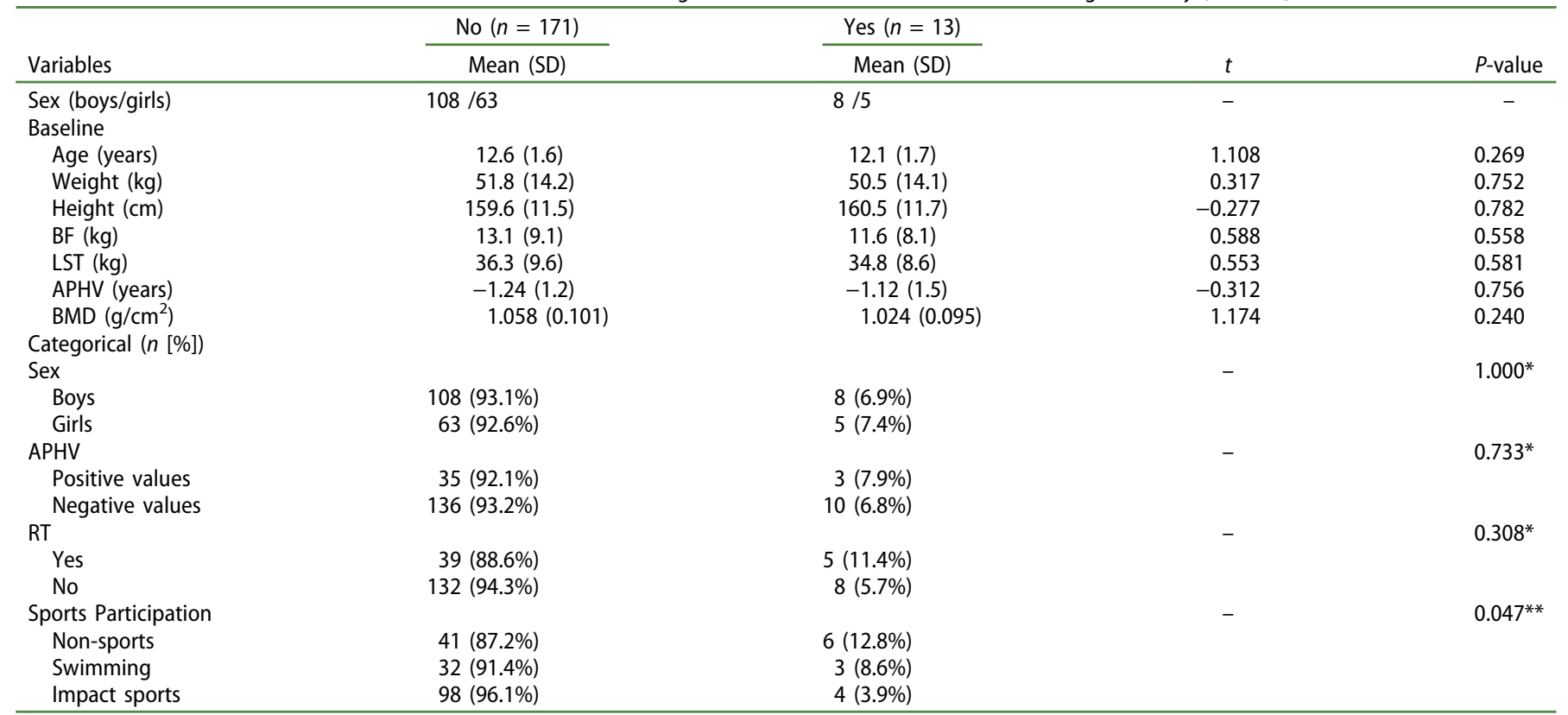

$\mathrm{DXA}=$ dual energy $\mathrm{X}$-ray absorptiometry; $\mathrm{BF}=$ body fatness; $\mathrm{LST}=$ lean soft tissue; $\mathrm{APHV}=$ age at peak height velocity; $\mathrm{SD}=$ standard deviation; $\mathrm{WB}=$ whole body; $\mathrm{BMD}=$ bone mineral density; $\mathrm{RT}=$ resistance training.

*Fisher's exact test.

${ }^{* *} x^{2}$ test. 
Table 2. Baseline characteristics of the adolescents stratified according to sports participation $(n=184)$.

\begin{tabular}{|c|c|c|c|c|}
\hline \multirow{2}{*}{ Groups } & Non-sports $(n=47)$ & Swimming $(n=35)$ & Impact Sports $(n=102)$ & ANOVA \\
\hline & Mean (SD) & Mean (SD) & Mean (SD) & $P$-value \\
\hline \multicolumn{5}{|l|}{ Baseline } \\
\hline Age (years) & $12.3(2.1)$ & $12.7(1.5)$ & $12.6(1.4)$ & 0.392 \\
\hline Height $(\mathrm{cm})$ & $155.3(11.1)$ & $162.3(10.3)^{* *}$ & $160.8(11.7)^{* *}$ & 0.006 \\
\hline $\mathrm{BF}(\mathrm{kg})$ & $12.2(7.6)$ & $11.7(8.4)$ & $13.8(9.6)$ & 0.380 \\
\hline LST (kg) & $31.3(6.6)$ & $39.5(9.4)^{* *}$ & $36.2(9.5)^{* *}$ & 0.001 \\
\hline APHV (years) & $-1.36(1.6)$ & $-1.05(1.05)$ & $-1.23(1.31)$ & 0.556 \\
\hline Sex & & & & $0.001 *$ \\
\hline Boys & 21 (44.7\%) & 20 (57.1\%) & 75 (73.5\%) & \\
\hline Age & & & & $0.878^{*}$ \\
\hline$\geq 15$ years & $6(12.8 \%)$ & 4 (11.4\%) & 12 (11.8\%) & \\
\hline APHV & & & & $0.725^{*}$ \\
\hline Positive values & $10(21.3 \%)$ & $5(14.3 \%)$ & $22(22.5 \%)$ & \\
\hline
\end{tabular}

Adolescents engaged in swimming and impact sport were taller $(P$-value $=0.006)$ and heavier $(P$-value $=0.005)$ than those not engaged in sports. Adolescents who were not involved in sports had lower LST than sports groups $(P$ value $=0.001$ ), even after adjustment by APHV (ANCOVA, $P$ value $=0.001 ; 10.9 \%$ of the variance observed on LST was explained by sports groups). BMD values were higher in adolescents engaged in impact sports $(P$-value $=0.002)$, even after adjustment by APHV (ANCOVA, $P$-value $=0.011 ; 5.3 \%$ of the variance observed on BMD was explained by sports groups). Sports participation was higher in boys than girls ( $P$ value $=0.001)$, while the practice of RT was higher in swimmers and impact sports athletes $(P$-value $=0.046)($ Table 2$)$.

Independently of confounders, the risk of fracture after 9 months of follow-up was lower in adolescents engaged in impact sports than in non-active ones (Model-5, $\mathrm{HR}=0.23$ [95\% Cl $=0.05-0.98]$ ), while swimming was not associated to lower fracture risk (Model-5, $\mathrm{HR}=0.49[95 \% \mathrm{Cl}=0.09-2.55]$ ) (Figure 2).

\section{Discussion}

This longitudinal study investigated the impact of different sports on stress fractures among adolescents and suggested that being engaged in impact sports lowers the risk of fractures.

We found that adolescents engaged in swimming and impact sports were taller, heavier and had higher LST than those adolescents not engaged in sports. Longitudinal data indicate no differences or only small differences in height between youth engaged and not engaged in non-organised sports (Beunen et al., 1992; Saris, Elvers, Van't Hof, \& Binkhorst, 1986). The difference observed could be attributed to the fact that our sample is composed of adolescents engaged in

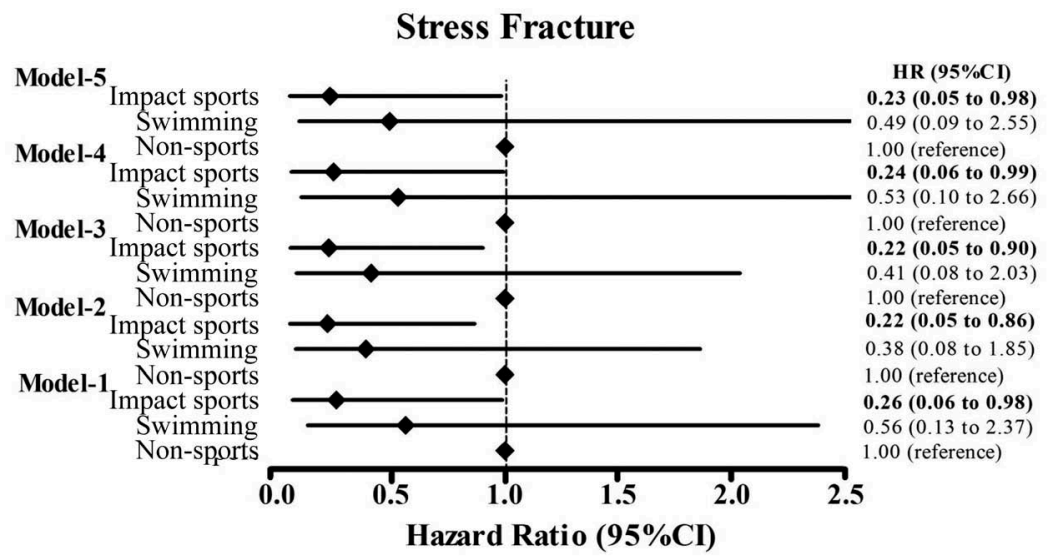

Model-5: Model-4 plus lean soft tissue (baseline)

Model-4: Model-3 plus bone mineral density (baseline and accrual)

Model-3: Model-2 plus age at peak height velocity (baseline and follow-up)

Model-2: Model-1 plus resistance training

Model-1: adjusted by sex, age and height

Figure 2. Risk of fracture during 9-month follow-up according to sports participation in adolescents (Brazil, $n=184$ ). 
organised sports, which requires previous selection of taller and stronger youth by coaches. In reference to body composition, Högström, Pietilä, Nordström, and Nordström (2012) analysed the percentage of muscle and fat mass on male and female adolescents and found that those who were engaged in sports presented significantly higher lean mass and lower body fat when compared to controls. As practical applications, they concluded that sports participation in adolescence requires both higher energy expenditure and manipulation of diet components, leading to control of body fatness and improvement of muscle mass (Högström et al., 2012).

Additional finding refers to the higher participation in sports by boys, concurring with literature (Fernandes et al., 2012; Hallal et al., 2006). Boys usually have more social and family support to engage in physical activities than girls (Gonçalves, Hallal, Amorim, Araújo, \& Menezes, 2007).

Our data showed that impact sports participation was associated with lower occurrence of fractures during the study. Tenforde, Sayres, McCurdy, Sainani, and Fredericson (2013) found that male adolescents who participated in basketball had $82 \%$ reduction in the risk of stress fractures compared to runners. Similarly, Milgrom, Simkin, Eldad, Nyska, and Finestone (2000) detected a 46\%-84\% reduction in stress fractures in infantry recruits who participated regularly in ball sports for 2 or more years before basic training. According to Frost and Schönau (2000), the development of optimal bone strength in children and adolescents relies primarily on muscle's mechanical load and strain on bones, thus sports participation affects bone strength and geometry in sites specifically led by the form of activity, which confers greater resistance to fracture (Janz, Thomas, Ford, \& Williams, 2015). Correspondingly, Calbet, Dorado, Diaz-Herrera, and Rodriguez-Rodriguez (2001) showed that amateur soccer players had increased BMD compared to age-matched control subjects. Taaffe, Robinson, Snow, and Marcus (1997) observed that high-impact sports promote increased BMD, and those adaptive changes to bone are specifically related to the form of activity (Agostinete et al., 2016; Janz et al., 2015).

Furthermore, the risk of fracture after 9 months was not lower in swimmers compared to non-sports adolescents. This finding could be partially explained by the fact that swimming does not present osteogenic effects such as impact sports does, like in soccer and basketball (Agostinete et al., 2016; Ferry, Lespessailles, Rochcongar, Duclos, \& Courteix, 2013). In sports with lower osteogenic potential, RT is recommended to promote improvements in bone health (Tenforde et al., 2015). On the other hand, it is noteworthy that BMD explained only partially the impact of sports participation on fracture risk, and thus, it is necessary to consider other pathways supporting the osteogenic effect of the physical exercise as protection against fractures, such as modifications on bone geometry, which are detected mainly in impact sports (Ferry et al., 2013).

Another finding of our study indicated that the incidence of fractures among adolescents was not associated with APHV, which is consistent with other studies (Blimkie et al., 1992; Gordon, Halton, Atkinson, \& Webber, 1991), but not all (Wren et al., 2012). It is important to highlight that lag in the development of bone mineral, relative to linear bone growth, and situational factors associated with acute sports participation (rather than an increase in time spent in sports) are recognised as contributing factors to incidence of fractures during the growth spurt. Wren et al. (2012) found significant effect of maturation on occurrence of bone fracture, but in Wren's publication, the participation in sports was assessed only by questionnaire, and it is not clear about the percentage of adolescents engaged in organised sports, as well as characteristics of the training routines.

As limitations we recognise the relative short period of development (but we are resuming follow-up to continue the analysis in this research area) and the impossibility of splitting the sample according to sex (even without significant differences related to bone fracture occurrence between boys and girls). Moreover, the absence of clinical records to assess bone fracture is a relevant point to overcome for futures studies. In this study, the absence of more details about RT (e.g., how many days per week, how many hours per day and weight lifted) should be mentioned due to the impact that RT variables can have on LST gains and bone variables. Finally, the absence of data about previous fractures at baseline is a relevant limitation due to its impact on the risk of reoccurrence fractures during the cohort (Wren et al. 2012).

Finally, the findings from this study indicate the importance of sports participation in adolescence in the reduction of stress fracture risk, especially impact sports. More importantly, these results could be relevant for recognising adolescents in danger of not reaching their potential for peak bone mass and later an increased risk of future fractures.

\section{Acknowledgements}

The authors would like to acknowledge São Paulo Research Foundation (FAPESP - Process numbers: 2013/06963-5 and 2015/13543-8).

\section{Disclosure statement}

No potential conflict of interest was reported by the authors.

\section{Funding}

The authors would like to acknowledge Fundação de Amparo à Pesquisa do Estado de São Paulo (FAPESP - Process numbers: 2013/06963-5 and 2015/13543-8) and Gilbert Elementary School, South Carolina.

\section{References}

Agostinete, R. R., Lynch, K. R., Gobbo, L. A., Lima, M. C., Ito, I. H., Luiz-deMarco, R., ... Fernandes, R. A. (2016). Basketball affects bone mineral density accrual in boys more than swimming and other impact sports: 9-mo follow-up. Journal of Clinical Densitometry, 19, 375-381. doi:10.1016/j.jocd.2016.04.006

Beunen, G. P., Malina, R. M., Renson, R., Simons, J., Ostyn, M., \& Lefevre, J. (1992). Physical activity and growth, maturation and performance: A longitudinal study. Medicine and Science in Sports and Exercise, 24, 576585. doi:10.1249/00005768-199205000-00012

Blimkie, C. J., Lefevre, J., Beunen, G. P., Renson, R., Dequeker, J., \& Van Damme, P. (1993). Fractures, physical activity, and growth velocity in adolescent Belgian boys. Medicine and Science in Sports and Exercise, 25, 801-808. doi:10.1249/00005768-199307000-00008

Brenner, J. S., \& Council on Sports Medicine and Fitness. (2007). Overuse injuries, overtraining, and burnout in child and adolescent athletes. Pediatrics., 119(6), 1242-1245. 
Calbet, J. A., Dorado, C., Diaz-Herrera, P., \& Rodriguez-Rodriguez, L. P. (2001). High femoral bone mineral content and density in male football (soccer) players. Medicine and Science in Sports and Exercise, 33, 16821687. doi:10.1097/00005768-200110000-00011

Fehling, P. C., Alekel, L., Clasey, J., Rector, A., \& Stillman, R. J. (1995). A comparison of bone mineral densities among female athletes in impact loading and active loading sports. Bone, 17, 205-210. doi:10.1016/87563282(95)00171-9

Fernandes, R. A., Reichert, F. F., Monteiro, H. L., Freitas Júnior, I. F., Cardoso, J. R., Ronque, E. R., \& De Oliveira, A. R. (2012). Characteristics of family nucleus as correlates of regular participation in sports among adolescents. International Journal of Public Health, 57(2), 431-435. doi:10.1007/ s00038-010-0207-7

Ferry, B., Lespessailles, E., Rochcongar, P., Duclos, M., \& Courteix, D. (2013). Bone health during late adolescence: Effects of an 8-month training program on bone geometry in female athletes. Joint, Bone, Spine, 80, 57-63. doi:10.1016/j.jbspin.2012.01.006

Frost, H. M., \& Schönau, E. (2000). The "muscle-bone unit" in children and adolescents: A 2000 overview. Journal of Pediatric Endocrinology and Metabolism, 13, 571-590. doi:10.1515/JPEM.2000.13.6.571

Gonçalves, H., Hallal, P. C., Amorim, T. C., Araújo, C. L., \& Menezes, A. M. (2007). Sociocultural factors and physical activity level in early adolescence. Revista Panamericana De Salud Pública, 22, 246-253. doi:10.1590/S1020-49892007000900004

Gordon, C. L., Halton, J. M., Atkinson, S. A., \& Webber, C. E. (1991). The contributions of growth and puberty to peak bone mass. Growth, Development, and Aging, 55, 257-262.

Gunter, K. B., Almstedt, H. C., \& Janz, K. F. (2012). Physical activity in childhood may be the key to optimizing lifespan skeletal health. Exercise and Sport Sciences Reviews, 40, 13-21. doi:10.1097/ JES.0b013e318236e5ee

Hallal, P. C., Reichert, F. F., Ekelund, U., Dumith, S. C., Menezes, A. M., Victora, C. G., \& Wells, J. (2006). Early determinants of physical activity in adolescence: Prospective birth cohort study. Bmj, 332, 1002-1007. doi:10.1136/bmj.38776.434560.7C

Högström, G. M., Pietilä, T., Nordström, P., \& Nordström, A. (2012). Body composition and performance: Influence of sport and gender among adolescents. Journal of Strength and Conditioning Research, 26, 17991804. doi:10.1519/JSC.0b013e318237e8da

Janz, K. F., Thomas, D. Q., Ford, M. A., \& Williams, S. M. (2015). Top 10 research questions related to physical activity and bone health in children and adolescents. Research Quarterly for Exercise and Sport, 86, 5-12. doi:10.1080/02701367.2014.995019

Kemper, H. C. (2006). Physical activity, physical fitness, and bone health. In N. Armstrong \& W. V. Mechelen (Eds.), Paediatric Exercise Science and Medicine (pp. 365-374). Oxford: Oxford.

Löfgren, B., Dencker, M., Nilsson, J. Å., \& Karlsson, M. K. (2012). A 4year exercise program in children increases bone mass without increasing fracture risk. Pediatrics, 129, e1468-76. doi:10.1542/ peds.2011-2274
Maffulli, N., \& Bruns, W. (2000). Injuries in young athletes. European Journal of Pediatrics, 159, 59-63. doi:10.1007/s004310050011

Milgrom, C., Simkin, A., Eldad, A., Nyska, M., \& Finestone, A. (2000). Using bone's adaptation ability to lower the incidence of stress fractures. The American Journal of Sports Medicine, 28, 245-251.

Mirwald, R. L., Baxter-Jones, A. D., Bailey, D. A., \& Beunen, G. P. (2002). An assessment of maturity from anthropometric measurements. Medicine and Science in Sports and Exercise, 34, 689-694.

Ribeiro-Dos-Santos, M. R., Lynch, K. R., Agostinete, R. R., Maillane-Vanegas, S., Turi-Lynch, B., Ito, I. H., ... Fernandes, R. A. (2016). Prolonged practice of swimming is negatively related to bone mineral density gains in adolescents. Journal of Bone Metabolism, 23, 149-155. doi:10.11005/ jbm.2016.23.3.149

Risser, W. L., Lee, E. J., LeBlanc, A., Poindexter, H. B., Risser, J. M., \& Schneider, V. (1990). Bone density in eumenorrheic female college athletes. Medicine and Science in Sports and Exercise, 22, 570-574. doi:10.1249/00005768-199010000-00005

Saris, W. H. M., Elvers, J. W. H., Van't Hof, M. A., \& Binkhorst, R. A. (1986) Changes in physical activity of children aged 6 to 12 years. In J. Rutenfranz, R. Mocellin, \& F. Klimt (Eds.), Children and exercise XII (pp. 121-130). Champaign, IL: Human Kinetics.

Strong, W. B., Malina, R. M., Blimkie, C. J., Daniels, S. R., Dishman, R. K., Gutin, B., .. Trudeau, F. (2005). Evidence based physical activity for school-age youth. The Journal of Pediatrics, 146, 732-737. doi:10.1016/j.jpeds.2005.01.055

Taaffe, D. R., Robinson, T. L., Snow, C. M., \& Marcus, R. (1997). High-impact exercise promotes bone gain in well-trained female athletes. Journal of Bone and Mineral Research, 12, 255-260. doi:10.1359/jbmr.1997.12.2.255

Tenforde, A. S., \& Fredericson, M. (2011). Influence of sports participation on bone health in the young athlete: A review of the literature. Pm $R, 3$, 861-867. doi:10.1016/j.pmrj.2011.05.019

Tenforde, A. S., Sainani, K. L., Sayres, L. C., Milgrom, C., \& Fredericson, M. (2015). Participation in ball sports may represent a prehabilitation strategy to prevent future stress fractures and promote bone health in young athletes. Pm\&R, 7, 222-225. doi:10.1016/j.pmrj.2014.09.017

Tenforde, A. S., Sayres, L. C., McCurdy, M., Sainani, K. L., \& Fredericson, M. (2013). Identifying sex-specific risk factors for stress fractures in adolescent runners. Medicine and Science in Sports and Exercise, 45, 18431851. doi:10.1249/MSS.0b013e3182963d75

Ubago-Guisado, E., Gómez-Cabello, A., Sánchez-Sánchez, J., GarcíaUnanue, J., \& Gallardo, L. (2015). Influence of different sports on bone mass in growing girls. Journal of Sports Sciences, 33, 1710-1718. doi:10.1080/02640414.2015.1004639

Vanderlei, F. M., Vanderlei, L. C., Bastos, F. N., Netto Júnior, J., \& Pastre, C. M. (2014). Characteristics and associated factors with sports injuries among children and adolescents. Brazilian Journal Physical Therapeutics, 18, 530-537. doi:10.1590/bjpt-rbf.2014.0059

Wren, T. A., Shepherd, J. A., Kalkwarf, H. J., Zemel, B. S., Lappe, J. M., Oberfield, S., ... Gilsanz, V. (2012). Racial disparity in fracture risk between white and nonwhite children in the United States. The Journal of Pediatrics, 161, 1035-1040. doi:10.1016/j.jpeds.2012.07.054 